\title{
Evaluation of Anorectal Afferent Pathway: Does It Help Overcome Unmet Diagnostic Needs in the Management of Fecal Incontinence?
}

\author{
Tae Hee Lee \\ Institute for Digestive Research, Soonchunhyang University Seoul Hospital, Seoul, Korea
}

Article: Defective conduction of anorectal afferents is a very prevalent pathophysiological factor associated to fecal incontinence in women

Mundet L, Cabib C, Ortega O, et al

(J Neurogastroenterol Motil 2019;25:423-435)

Fecal incontinence (FI) is a complex disease resulting from overflow, reduced storage capacity, weakness of internal anal sphincter, disruption of external anal sphincter or puborectalis muscle and decreased perception of rectal sensation. ${ }^{1}$ The clinical assessment including a detailed history, physical examination, and digital rectal examination should be taken to arrive at an accurate diagnosis, establish rapport with the patient, and making a proper management strategy for diagnostic testing and treatment. Diagnostic testing currently available includes endoscopy, anorectal manometry with sensory testing, anal endosonography/magnetic resonance image, defecography, pudendal nerve motor latency, balloon expulsion test, and saline infusion test (Table). The extent of diagnostic testing is influenced by the availability of tests and the clinical features such as symptom severity and response of conservative management. ${ }^{2}$

Although the contribution of anal weakness to FI is well recognized, the role of altered rectal sensation in FI is under-recognized. Rectal sensation is evaluated by progressively distending a latex balloon manually or by distending a polyethylene balloon with a barostat. ${ }^{3}$ Rectal hyposensitivity is clinically defined as elevated perception thresholds to rectal balloon distension. ${ }^{3}$ When rectal sensation is reduced, this condition allows stool to enter the anal canal and possibly leak before the external anal sphincter contracts. It means that rectal hyposensitivity causes impaired sensory-aware mechanism to properly trigger continence action. However, the pathophysiology of rectal hyposensitivity remains unknown. It is plausible that RH is secondary to afferent nerve dysfunction. However, rectal sensation assessed by distending a latex balloon during anorectal manometry examination reflects rectal mechanoreceptor's distension sensitivity and is affected by rectal compliance. This technique cannot clarify whether afferent neural pathway is intact (ie, primary rectal hyposensitivity).

A sensory evoked potential (SEP) is an electrical potential recorded from the nervous system following presentation of an electrical stimulus. ${ }^{4}$ The measurement of SEP to anal/rectal electrical stimulation (ASEP/RSEP) is an objective neurophysiological technique for assessing the integrity of afferent pathways from anorectal structures. ${ }^{5}$ This technique has been assessed in healthy volunteers, ${ }^{6-8}$ irritable bowel syndrome, ${ }^{9,10}$ and constipation. ${ }^{11}$ At the

Received: June 20, 2019 Revised: None Accepted: July 8, 2019

(.) This is an Open Access article distributed under the terms of the Creative Commons Attribution Non-Commercial License (http://creativecommons. org/licenses/by-nc/4.0) which permits unrestricted non-commercial use, distribution, and reproduction in any medium, provided the original work is properly cited.

*Correspondence: Tae Hee Lee, MD, PhD Institute for Digestive Research, Digestive Disease Center, Soonchunhyang University Seoul Hospital, 59 Daesagwan-ro, HannamDong, Yongsan-Gu, Seoul 04401, Korea Tel: +82-2-710-3084, Fax: +82-2-709-9696, E-mail: iman0825@schmc.ac.kr 
Table. Clinical Assessment and Diagnostic Testing Currently Available

\begin{tabular}{|c|c|}
\hline Items & Measurements \\
\hline \multirow[t]{9}{*}{ Detailed history } & Onset and precipitating events \\
\hline & Duration, severity, and timing \\
\hline & Stool consistency and urgency \\
\hline & Co-existing problems/surgery/urinary incontinence/back injury \\
\hline & Obstetric history \\
\hline & Drugs, caffeine, and diet \\
\hline & Clinical subtypes-passive, urge incontinence, or fecal seepage \\
\hline & Clinical grading of severity \\
\hline & History of fecal impaction \\
\hline \multirow[t]{5}{*}{ Physical examination } & Back and the lower limbs \\
\hline & Perianal inspection \\
\hline & Prolapsed hemorrhoid \\
\hline & Anal deformity \\
\hline & Dermatitis resulting from frequent soiling \\
\hline \multirow[t]{3}{*}{ Digital rectal examination } & Anal sphincter tone and strength \\
\hline & Perineal descent \\
\hline & Rectal prolapse \\
\hline \multirow[t]{2}{*}{ Endoscopy } & Mucosal disease \\
\hline & Neoplasia \\
\hline \multirow[t]{3}{*}{ Anorectal manometry with sensory testing } & Functional weakness of the IAS/EAS \\
\hline & Abnormal rectal sensation \\
\hline & Rectal compliance \\
\hline Anal endosonography/MRI & Structural defects of the anal sphincter \\
\hline Electromyography & Structural defects of the anal sphincter \\
\hline \multirow[t]{2}{*}{ Rectal barostat } & Rectal compliance \\
\hline & Abnormal rectal sensation \\
\hline \multirow[t]{2}{*}{ Defecography } & Suspected rectal prolapse \\
\hline & Poor rectal evacuation \\
\hline Pudendal nerve terminal latency & Motor efferent pathways \\
\hline Balloon expulsion test & Impaired evacuation in patients with fecal seepage or fecal impaction \\
\hline Saline infusion test & Clinical improvement after treatment \\
\hline
\end{tabular}

IAS, internal anal sphincter; EAS, external anal sphincter; MRI, magnetic resonance image.

present time, little is known about the role of altered sensory pathways as a pathophysiological mechanism of patients with FI. In this issue of Journal of Neurogastroenterology and Motility, Mundet et $\mathrm{al}^{12}$ assessed ASEP/RESP with neurophysiologic technique in 19 healthy volunteers (HVs) and 175 women with FI. The main finding is that abnormal conduction of anorectal afferents as well as mechanical anal sphincter dysfunctions contributes to pathophysiology of FI (Figure). ASEP latencies were significantly longer in patients with in HVs and approximately half of patients had ASEP latency outside the reference values. RESP latencies were significantly longer in patients than in HVs and approximately $50 \%$ of patients had abnormal RESP parameters (including latencies and amplitude). Patients had significantly reduced activated cortical area compared than HVs. This difference in activation of cortical area between
HVs and patients do not suggests that brain cortex plays a role in the pathogenesis of FI among the patients enrolled in this study. Impaired sensory perception and integration processing may cause reduced activated cortical area in the patients.

This study is the first to indicate that application of ASEP/ RESP neurophysiology technology provides novel insights regarding the pathogenesis of FI. The presence of impaired conduction in anorectal afferent pathways may be important in explaining the reason why sacral neuromodulation improves symptoms of FI in some patients with any mechanical effect on anal sphincter function. This evolution also offers great promise in understanding of the contribution of impaired rectal afferents and developing more specific treatments for patients with FI. However, this study does not involve the data of ASEP/RESP neurophysiology test regarding 
Delayed conduction through sensory anorectal pathways in fecally incontinent women

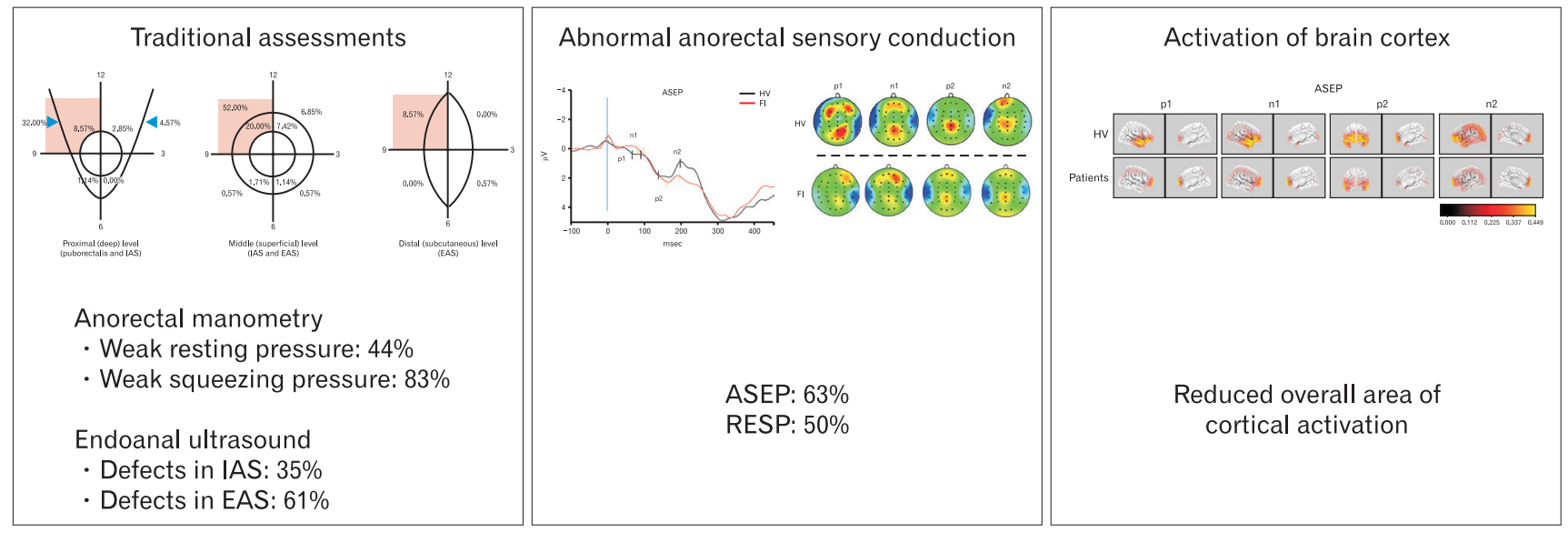

Figure. Visual representation of the key findings. IAS, internal anal sphincter; EAS, external anal sphincter; HV, healthy volunteers; FI, fecal incontinence; ASEP, anal sensory evoked potential; RESP, rectal sensory evoked potential. Reproduced from Mundet et al. ${ }^{12}$

rectal hypersensitivity which may contribute to the symptom of urgency in $\mathrm{FI}$ and is often observed in patients with $\mathrm{FI} .^{13}$ In addition, it challenges to perform the measurement of ASEP/RESP through this neurophysiological technique in every practice environment. Now, this technique is not in routine clinical use but seems to provide useful insights into the mechanism of anorectal sensory dysfunction. Further studies with SEP analysis in response to electrical stimuli are also necessary to understand functional consequences and clinical utility of delayed anorectal afferent pathways for stratifying patients with FI to medical, behavioral and surgical therapies.

Financial support: This work was supported by the Soonchunhyang University Research Fund.

\section{Conflicts of interest: None.}

Author contributions: Tae Hee Lee designed, wrote, and critically reviewed the study.

\section{References}

1. Wald A. Clinical practice. Fecal incontinence in adults. $\mathrm{N}$ Engl J Med 2007;356:1648-1655.

2. Bharucha AE. Fecal incontinence. Gastroenterology 2003;124:16721685 .

3. Gladman MA, Lunniss PJ, Scott SM, Swash M. Rectal hyposensitivity. Am J Gastroenterol 2006;101:1140-1151.

4. Nissen TD, Brock C, Graversen C, et al. Translational aspects of rectal evoked potentials: a comparative study in rats and humans. Am J Physiol Gastrointest Liver Physiol 2013;305:G119-G128.

5. Remes-Troche JM, Tantiphlachiva K, Attaluri A, et al. A bi-directional assessment of the human brain-anorectal axis. Neurogastroenterol Motil 2011;23:240-248, e117-e118.

6. Hobday DI, Hobson AR, Sarkar S, Furlong PL, Thompson DG, Aziz Q. Cortical processing of human gut sensation: an evoked potential study. Am J Physiol Gastrointest Liver Physiol 2002;283:G335-G339.

7. Garvin B, Lovely L, Tsodikov A, Minecan D, Hong S, Wiley JW. Cortical and spinal evoked potential response to electrical stimulation in human rectum. World J Gastroenterol 2010;16:5440-5446.

8. Loening-Baucke V, Read NW, Yamada T. Further evaluation of the afferent nervous pathways from the rectum. Am J Physiol 1992;262(5 Pt 1):G927-G933.

9. Sinhamahapatra P, Saha SP, Chowdhury A, Chakrabarti SK, Ghosh A, Maiti B. Visceral afferent hypersensitivity in irritable bowel syndrome-evaluation by cerebral evoked potential after rectal stimulation. Am J Gastroenterol 2001;96:2150-2157.

10. Rössel P, Pedersen P, Niddam D, Arendt-Nielsen L, Chen AC, Drewes AM. Cerebral response to electric stimulation of the colon and abdominal skin in healthy subjects and patients with irritable bowel syndrome. Scand J Gastroenterol 2001;36:1259-1266.

11. Burgell RE, Lelic D, Carrington EV, et al. Assessment of rectal afferent neuronal function and brain activity in patients with constipation and rectal hyposensitivity. Neurogastroenterol Motil 2013;25:260-267, e167e168.

12. Mundet L, Cabib C, Ortega O, et al. Defective conduction of anorectal afferents is a very prevalent pathophysiological factor associated to fecal incontinence in women. J Neurogastroenterol Motil 2019;25:423-435.

13. Bharucha AE. Management of fecal incontinence. Gastroenterol Hepatol (NY) 2008;4:807-817. 